\title{
A NON-SYSTEMATIC REVIEW OF EVIDENCE-BASED PRACTICE WITHIN SPEECH PATHOLOGY IN AUSTRALIA
}

\author{
Sharynne McLeod \\ Charles Sturt University, Australia
}

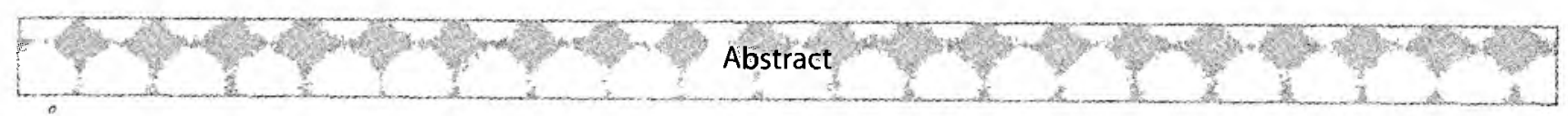

In this non-systematic review, evidence-based practice (EBP) in Australian speech pathology research and practice is examined. Many Australian researchers arecontributing to the theoreticalevidencethrough systematicreviews, randomised controlled trials, and other clinical research. Additionally, Australian researchers are integrating international theoretical evidence via speechBITE'M and other initiatives. Australian speech pathologists' clinical expertise is supported via Speech Pathology Australia and an example of the implementation ofEBP in clinical contexts is the NSWEBP Network. Within Australia, research attention also has been directed towards the client's choice and the client's voice. This paper acknowledges limitations of implementing EBP in Australia: suggesting that inclusion of the client's voice could be formalised and that additional research needs to be undertaken to address practical differences in service delivery models between Australian and international contexts.

Key words: Evidence-based practice, Australia, professional practice, speech-language pathology, ICF.

$\mathrm{E}$ vidence-based practice (EBP) is increasingly encouraged within the health and medical professions as a method to underpin clinical decision making. Based on the definition of Sackett, Rosenberg, Gray, Hayes, and Richardson (1996), EBP is considered to have three components: theoretical evidence, clinical expertise and client's choice. In this paper, these three components will be considered by drawing on examples of research and practice undertaken within the field of speech pathology in Australia. While the author has aimed to represent a broad overview of EBP in Australia, it is acknowledged that this paper does not present a systematic review.

To contextualise this paper, Australia is a country of over 20 million people and is one of the most multicultural countries in the world (Hugo, 2002). It is primarily populated along the coasts with the largest population centres being Sydney, Brisbane and Melbourne on the east coast, whereas inland Australia is sparsely populated. Distance and remoteness bring challenges to the provision of health care within Australia. Healthcare in Australia is freely available for all through government funding and there is also opportunity for privately funded healthcare. Speech pathology is provided through the health, education and disability sectors by the Australian government as well as through private practices; however, this non-centralised approach coupled with geographical barriers can mean that some people do not have access to the amount of speech pathology services they require (e.g., McLeod \& McKinnon, 2007; O'Callaghan, McAllister \& Wilson, 2005a). The traditions of speech pathology practice in Australia were originally influenced by Britain; however, over the years the Australian speech pathology profession has been acknowledged for drawing on, synthesising and enhancing perspectives from throughout the world. Currently, there are eight universities that provide professional preparation programs for speech pathologists and Speech Pathology Australia (www.speechpatholo- gyaustralia.org.au) is the peak professional body for speech pathologists.

\section{Theoretical evidence}

The first component of EBP mentioned by Sackett et al. (1996) is theoretical evidence. According to Australia's National Health and Medical Research Council (NHMRC) (2000,p.7-8) the highest level of evidence for "assessing clinical and public health interventions" is "a systematic review of all relevant randomised controlled trials". The next highest is "evidence obtained from at least one properly designed randomised controlled trial". Key Australian speech pathology researchers have been at the cutting edge in undertaking systematic research regarding interventions for people with communication disorders. For example, an Australian, Angela Morgan has co-authored a Cochrane Systematic Review on the topic of intervention for developmental apraxia of speech (Morgan \& Vogel, 2006). The Australian Stuttering Research Centre (ASRC) has conducted randomised controlled trials to demonstrate the effectiveness of the Lidcombe Program for preschool children who stutter (e.g., Jones et al., 2005; Jones et al., in press). Randomised controlled trials also have been conducted in Australia regarding interventions for chronic cough (Vertigan, Theodoros, Gibson, \& Winkworth, 2006), the training of communication partners of people with traumatic brain injury (Togher, McDonald, Code, \& Grant, 2004) and the training of volunteers to assist people who have aphasia (Worrall \& Yiu, 2000). Additionally, there is much research being undertaken within Australia that would be categorised

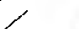


by NHMRC as providing "lower" levels of evidence, yet is important for understanding the effectiveness and efficiency of intervention for people with communication disorders (Code, 2000).

Australian researchers have also been involved in synthesizing available international evidence for speech pathology practice. Notably, a group of Australian speech pathology academics primarily from LaTrobe University have compiled and analysed evidence in their book Evidence based practice in speech patbology (Reilly, Douglas \& Oates, 2004). This book critiques theoretical evidence for working with clinical populations including people who have aphasia, acquired brain injury, stuttering, voice disorders, dysphagia, developmental language disorders, motor speech disorders, articulation and phonological disorders and those who use augmentative and alternative communication. Recently, Speech Pathology Australia, in association with The University of Sydney has launched speechBITE ${ }^{\mathrm{TM}}$ (www.speechbite.com) "[t]o enable speech pathology clinicians and researchers to efficiently access the best available evidence to inform speech pathology practice and research". The free online database catalogues systematic reviews, randomised controlled trials (RCTs), non-randomised controlled trials (non-RCTs), case series and single case experimental designs (SCEDs) that are relevant to speech pathology practice. To enable clinicians to more easily interpret the scientific quality of the research, RCTs, non-RCTs and SCED studies are given a methodological rating and papers are listed according to their methodological quality. speechBITE ${ }^{\mathrm{TM}}$ is the most recently launched of four databases which have been developed in Australia to facilitate the use of EBP in clinical decision making. The others include PEDro for physiotherapy (www.pedro.fhs.usyd.edu.au), OT Seeker for occupational therapy (www.otseeker.com) and PsycBITE ${ }^{\mathrm{TM}}$ for people working in the field of acquired brain impairment (www. psycbite.com).

One of the difficulties that Australians face with employing theoretical evidence generated in some international speech pathology studies, is that the recommended dosage of intervention is not possible within the Australian health, education and disability sectors; frequently due to limited funding for services. For example, many international studies recommend provision of intervention twice a week to children; a service delivery model that is rare within Australia. Within the United Kingdom, Glogowska, Roulstone, Enderby, and Peters (2000) demonstrated in a pragmatic randomised controlled trial that if children do not receive a high enough dosage of intervention, then speech pathology outcomes may be negligible. Furthermore, speech pathologists are not employed by the government education system of the largest state within Australia (New South Wales [NSW]), so evidence-based interventions that have been designed for school settings are rarely able to be implemented.

In addition to the importance of considering the theoretical evidence, there are two other components to EBP as espoused by Sackett et al. (1996, p. 71):

"Evidence based medicine is not "cookbook" medicine.

Because it requires a bottom up approach that integrates the best external evidence with individual clinical expertise and patients' choice, it cannot result in slavish, cookbook approaches to individual patient care. External clinical evidence can inform, but can never replace, individual clinical expertise."

\section{Clinical expertise}

Speech pathology graduates from Australian universities are conversant with evidence-based practice guidelines. Each of these university courses are accredited by Speech Pathology Australia and each graduate has met Competency-Based Occupational Standards (CBOS) (Speech Pathology Australia, 2001) demonstrating their clinical expertise. For example, in order to plan clinical intervention, entry level speech pathologists must demonstrate that they can "... give a rationale for decisions made with reference to: the client's communication/swallowing history, the critical appraisal of evidence in current literature and research, clinical reasoning." (Speech Pathology Australia, 2001, p. 9).

Speech Pathology Australia supports the ongoing development of clinical expertise through evidence-based practice in many ways. It publishes both an academic journal (International Journal of Speech-Language Pathology, previously called Advances in Speech-Language Pathology) and a clinical journal (ACQuiring Knowledge in Speech, Language and Hearing) that has a regular column titled "What's the evidence for...?" The association organises an annual scientific conference that is attended by hundreds of speech pathologists (including both national and international delegates). Additionally, it organises regular professional development courses in each state that are presented by key researchers and clinicians. Speech Pathology Australia also provides a professional self regulation (PSR) program to support and recognise continuing professional development of Australian speech pathologists. Those who are involved in the PSR program are able to use the postnominals, CPSP (certified practicing speech pathologist).

Around Australia speech pathologists are encouraged to apply evidence-based practice to their management of people with communication disorders. The NSW Speech Pathology EBP Network (2008) is possibly the most formalized method where this takes place. This EBP network was established in 2002 so that speech pathologists could collaboratively examine evidence to enhance their practice and is currently organised around the following clinical groups: augmentative and alternative communication, tracheostomy and critical care, paediatric language, paediatric phonology, paediatric feeding, adult swallowing, adult speech, adult language, cleft palate. Each clinical group has their own terms of reference and presents critically appraised papers and topics (CAPs and CATs) on the website and at their annual conference.

Additionally, a number of Australian researchers are involved in translation of research to clinical practice to support the development of clinical expertise. Onslow, Jones, O'Brian, and Menzies (in press) have recently written a tutorial paper to facilitate consumers' understanding and interpretation of clinical trials of stuttering treatments. A special issue of Advances in Speech-Language Pathology (McLeod, 2006) provided readers with ten different perspectives from international experts on intervention approaches for Jarrod, a seven-year-old with unintelligible speech. The special issue 
was accompanied by online video files to enable clinicians to develop their clinical expertise by reflecting on their clinical decision making for Jarrod.

Shelton (1993, p. 175) indicated that "Clinicians need to make skillful use of a tremendous store of information..." Australian researchers have conducted research into speech pathologists' professional practice. For example, McLeod and Baker (2004) examined Australian speech pathologists' clinical practice for children with speech impairment and Watts Pappas, McLeod, McAllister and McKinnon (2008) studied Australian speech pathologists' practices for working with families.

\section{Client's choice}

Many Australian researchers have a commitment to exploration of the client's choice and the client perspective. For example, Australian speech pathology researchers have talked with people who have aphasia (Cruice, Worrall \& Hickson, 2006), adolescents who stutter (Herane, Packman, Onslow \& Quine, in press), stakeholders involved with people who had a traumatic brain injury (Larkins, Worrall \& Hickson, 2004), parents of children who have undergone newborn infant hearing screening (Mazlan, Hickson, \& Driscoll, 2006) and siblings of children with speech impairment (Barr, McLeod \& Daniel, 2008). Australian research has also considered clients' opinions on the barriers of accessing speech pathology services when they are in rural and remote locations (O'Callaghan et al., 2005b). Kovarsky (2008, p. 47) indicated that "The current version of EBP needs to be reformulated to include subjective voices from the life-worlds of clients as a form of evidence." Although not considered on the NHMRC levels of evidence, exploration and consideration of the client's voice is important within the Australian research context.

\section{Summary}

Many Australian speech pathologists have incorporated EBP within their clinical decision-making, strongly supported by Speech Pathology Australia. Along with many others throughout the world, Australian researchers have embraced and contributed to understanding the three discreet and interconnected aspects of EBP: theoretical evidence, clinical expertise and client's choice. In this paper it is suggested that formalised EBP categories could expand to further acknowledge client's voices. Ray Kent, in his role as Vice President for Research and Technology of the American Speech-Language-Hearing Association (ASHA) described the application of EBP to the speech pathology and audiology professions in the USA as follows "Evidencebased practice (EBP) is a challenging but attainable goal for audiology and speech-language pathology. Our professions have made rapid progress in developing the foundations for EBP. To be sure, a great deal of work remains to be done, but we have learned from the experiences of other professions and have built our own systems to support EBP" (Kent, 2006, p. 268). His words can be echoed in the Australian context.

\section{References}

Code, C. (2000). The problem with RCTs. RCSLT Bulletin, 1415. March.
Cruice, M. N., Worrall, L. E. \& Hickson, L. M. H. (2006). Perspectives on quality of life by people with aphasia and their family: Suggestions for successful living. Topics in Stroke Rehabilitation, 13, 14-24.

Glogowska, M., Roulstone, S., Enderby, P., \& Peters, T. J. (2000). Randomised controlled trial of community based speech and language therapy in preschool children. British Medical Journal, 321, 1-5. 14 October.

Hearne, A., Packman, A., Quine, S., \& Onslow, M. (2008). Stuttering and its treatment in adolescence: The perceptions of people who stutter. Journal of Fluency Disorders. 33, 2, 81-98.

Hugo, G. (2002). Year book Australia: Centenary article-A century of population change in Australia. Retrieved December 12, 2003 from http://www.abs.gov.au/Ausstats/abs@.nsf/Lookup/ 0B82C2F2654C3694CA2569DE002139D9.

Jones, M., Hearne, A., Onslow, M., Packman, A., Ormond, T., Williams, S., Schwarz, I., \& O'Brian, S. (2008). Extended follow up of a randomised controlled trial of the Lidcombe Program of Early Stuttering Intervention. International Journal of Language and Communication Disorders. DOI: 10.1080/136828 20801895599.

Jones, M., Onslow, M., Packman, A., Williams, S., Ormond, T., Schwarz, I., et al. (2005). Randomised controlled trial of the Lidcombe Program for early stuttering intervention. British Medical Journal, 331, 7518, 659-663.

Kent, R. D. (2006). Evidence-based practice in communication disorders: Progress not perfection. Language, Speech, and Hearing Services in Schools, 37, 4, 268-270.

Kovarsky, D. (2008). Representing voices from the life-world in evidence-based practice. International Journal of Language and Communication Disorders, 43(1 supp 1), 47- 57.

Larkins, B. M., Worrall, L. E. \& Hickson, L. M. H. (2004). Stakeholder opinion of functional communication activities following traumatic brain injury. Brain Injury, 18, 691-706.

Mazlan, R., Hickson, L. M. H. \& Driscoll, C. (2006). Measuring parent satisfaction with a neonatal hearing screening program. Journal of the American Academy of Audiology, 17, 4, 253-264.

McLeod, S. (2006). Editorial: Perspectives on a child with unintelligible speech. Advances in Speech-Language Pathology, 8, 3, 153-155.

McLeod, S., \& Baker, E. (2004). Current clinical practice for children with speech impairment. In B. E. Murdoch, J. Goozee, B. M. Whelan \& K. Docking (Eds.), Proceedings of the 26th World Congress of the International Association of Logopedics and Phoniatrics. Brisbane: University of Queensland.

Morgan, A., \& Vogel, A. (2006). Intervention for developmental apraxia of speech. Cochrane Database of Systematic Reviews Issue 4. Art. No.: CD006278., DOI: 10.1002/14651858. CD14006278.

National Health and Medical Research Council (NHMRC) (2000). How to use the evidence: Assessment and application of scientific evidence. Canberra: Commonwealth of Australia.

NSW Speech Pathology EBP Network (2008). NSW speech pathology evidence based practice. Retrieved June 16, 2008 from http:// www.ciap.health.nsw.gov.au/specialties/ebp_sp_path/index. html.

O'Callaghan, A. M., McAllister, L., \& Wilson, L. (2005a). Barriers to accessing rural paediatric speech pathology services: Health care consumers' perspectives. Australian Journal of Rural Health, $13,3,162-171$. 
O'Callaghan, A. M., McAllister, L., \& Wilson, L. (2005b). Consumers' proposed solutions to barriers to access of rural and remote speech pathology services. Advances in Speech-Language Patbology, 7, 2, 58-64.

Onslow, M., Jones, M., O’Brian, S., \& Menzies, R. (in press). Defining, identifying, and evaluating clinical trials of stuttering treatments: A tutorial. American Journal of Speech-Language Pathology.

Reilly, S., Douglas, J., \& Oates, J. (2004). Evidence based practice in speech pathology. Whurr Publishers: London.

Sackett, D. L., Rosenberg, W. M. C., Gray, J. A. M., Hayes, R. B., \& Richardson, W. S. (1996). Evidence-based medicine: What it is and what is isn't. British Medical Journal, 312, 71-72.

Speech Pathology Australia (2001). Competency-based occupational standards (CBOS) for entry level. Melbourne: The Speech $\mathrm{Pa}-$ thology Association of Australia.
speechBITE ${ }^{\mathrm{TM}}$ (2008). speechBITE ${ }^{\mathrm{TM}}$ Speech pathology database for best interventions and treatment efficacy. Retrieved June 16, 2008 from http://www.speechbite.com.

Togher, L., McDonald, S., Code, C., \& Grant, S. (2004). Training communication partners of people with traumatic brain injury. A randomised controlled trial, Aphasiology, 18, 4, 313-335.

Vertigan, A. E., Theodoros, D. G., Gibson, P. G., Winkworth, A. L. (2006). Efficacy of speech pathology management for chronic cough: A randomised placebo controlled trial of treatment efficacy. Thorax, 61, 12, 1065-1069.

Watts Pappas, N., McLeod, S., McAllister, L., \& McKinnon, D. H. (2008). Parental involvement in speech intervention: A national survey. Clinical Linguistics and Pbonetics, 22, 4, 335-344.

Worrall L., \& Yiu E. (2000). Effectiveness of functional communication therapy by volunteers for people with aphasia following stroke. Aphasiology, 14, 9, 911-924. 